\title{
Association Study of Estrogen Receptor Alpha Gene Polymorphisms with Spontaneous Abortion: Is This a Possible Reason for Unexplained Spontaneous Abortion?
}

\author{
Negin Anousha, ${ }^{1}$ Arash Hossein-Nezhad, ${ }^{2,3}$ Firouzeh Biramijamal, ${ }^{4}$ Ali Rahmani, ${ }^{1}$ \\ Zhila Maghbooli, ${ }^{3}$ Elahe Aghababaei, ${ }^{3}$ and Shahram Nemati ${ }^{3}$ \\ ${ }^{1}$ Department of Genetics, Ahar Branch, Islamic Azad University, Ahar 54511, Iran \\ ${ }^{2}$ Department of Medicine, Section of Endocrinology, Nutrition, and Diabetes, Vitamin D, Skin and Bone Research Laboratory, \\ Boston University Medical Center, Boston, MA 02118, USA \\ ${ }^{3}$ Endocrinology and Metabolism Research Institute, Tehran University of Medical Sciences, Tehran 14114, Iran \\ ${ }^{4}$ Department of Medical Genetics, National Institute of Genetic Engineering and Biotechnology, Tehran 14178, Iran
}

Correspondence should be addressed to Arash Hossein-Nezhad; arash_hsi@yahoo.com

Received 24 April 2013; Accepted 11 September 2013

Academic Editor: Andre Van Wijnen

Copyright (C) 2013 Negin Anousha et al. This is an open access article distributed under the Creative Commons Attribution License, which permits unrestricted use, distribution, and reproduction in any medium, provided the original work is properly cited.

\begin{abstract}
Estrogen plays a crucial role in fetal and placental development through estrogen receptors. Association of estrogen receptor alpha gene (ESR1) polymorphisms with spontaneous abortion has been shown in some studies. Our main goal was to study the potential association of spontaneous abortion with the ESR1 gene variations (PvuII and XbaI) in fetal tissue. Totally, 161 samples were recruited including 80 samples of formalin-fixed paraffin-embedded fetal tissue from spontaneous abortion and 81 samples of normal term placental tissue. The restriction fragment length polymorphism (RFLP) method was performed for genotyping the rs2234693 (A/G XbaI) and rs9340799 (T/C PvuII) single nucleotide polymorphisms located in intron 1 of ESR1. The results have been confirmed by DNA sequencing analysis. The different genotypes distribution was detected in two study groups. Haplotype analysis indicated that $p p x x$ is protective genotype against spontaneous abortion $(P=0.01)$. In conclusion, the potential role of ESR1 genetic variation in spontaneous abortion might be valuable in high-risk subjects, and that needs to be confirmed with future studies.
\end{abstract}

\section{Introduction}

Estrogen receptors (ER) are group of proteins classified as nuclear receptors and member of ligand-activated transcription factors. Estrogen actions on target tissues are mediated by the ER [1]. Estrogen is a major endocrine hormone, playing a crucial role throughout the entire pregnancy such as fetal development, uteroplacental blood flow, implantation, regulation of reproduction, and biosynthesis of progesterone $[2,3]$. It has been reported that a huge amount of estrogen is produced by human placenta during pregnancy. Recent studies showed that estrogen seemed to have a vital role in the development of placental villous blood vessel. A noticeable increase in biosynthesis of placental estrogen was observed in the early stages of pregnancy when the placental vascular network starts to develop [4]. The autocrine role of placenta in estrogen production is critical for trophoblast cells differentiation [5]. Blockage of estrogen receptor as a consequence of tamoxifen, given orally to female bonnet monkeys, led to pregnancy inhibition through postovulatory period [6]. ER $\alpha$ and $\mathrm{ER} \beta$, as two types of ER, are encoded by ESR1 and ESR2 genes located on chromosome 6 and chromosome 14, respectively $[7,8]$. ER $\alpha$ is more abundant and exists in all human reproductive tissues [2]. Expression of $\operatorname{ER} \alpha$, but not $\operatorname{ER} \beta$, has been observed in cultured human trophoblast cells before and after differentiation [9]. ER $\alpha$ knockout female mice were anovulatory and infertile. The uteri of these mice did not respond to estrogen [10].

Spontaneous abortion (SA) is an unintentional end of pregnancy before the stage that the fetus is able to survive 
independently [11]. SA is one of the most common complications of pregnancy, particularly in the first trimester, which occurs in approximately $15 \%-20 \%$ of clinically recognized pregnancies $[12,13]$. The pathogenesis of SA is multifactorial, and approximately $40 \%-50 \%$ of recurrent spontaneous abortions remain idiopathic [11]. Genetic variations might be noticeable in idiopathic SA, and the association of several genetic variations with SA has been reported [14]. The ESR1 was one of the best candidate genes in SA association studies, and its polymorphisms were involved in SA $[3,15]$. Furthermore, the role of numerous polymorphic variants in the fertility candidate genes including ESR1 is consistent with this hypothesis $[16,17]$.

The ESR1 has been reported as an extremely polymorphic gene, such that studies determined more than 2200 SNPs of this gene [18]. The rs2234693 (T>C: PvuII) and rs9340799 $(\mathrm{A}>\mathrm{G}$ : XbaI) located in the intron 1 have been identified as the most common and widely studied SNPs in related investigations [18, 19]. These common ESR1 polymorphisms have been reported in relation with SA [3], infertility [20], successful IVF (in vitro fertilization) [18, 21], and preeclampsia [22]. Although these intronic variations ( $P v u I I$ and $\mathrm{XbaI}$ ) were not involved in protein changing, they have been suggested as genetic markers for some ESR1-related disorders due to a linkage with other functional sequences affecting ESR1 function or expression [21, 22].

In spite of the growing body of evidence regarding the potential role of ESR1 genetic variations in SA, the association of these polymorphisms (PvuII and XbaI) has not been investigated in human fetal genome.

In this study, the possible association of PvuII and XbaI polymorphisms of the ESR1 with spontaneous abortion was evaluated in spontaneously aborted fetus tissue in comparison with placental tissue of healthy term newborns.

\section{Materials and Methods}

2.1. Subjects. The study protocol was approved by ethics committee of EMRI (Endocrinology and Metabolism Research Institute of Tehran University of Medical Sciences). Informed written consent was obtained from all participants. Eighty samples of formalin-fixed paraffin-embedded fetal tissue from spontaneous abortion diagnosed previously were included as a case group. These samples were collected from Emam-Sajad and Ghiasi Hospitals of Tehran cooperating with EMRI.

The samples of this group were selected by the inclusion criteria of containing fetal tissue from spontaneous abortion in the first trimester of gestation during natural pregnancies and of unknown etiology confirmed by a gynecologist and a pathologist. All of the case samples were karyotyped, and the samples with abnormal karyotype and infections including toxoplasmosis, rubella, cytomegalovirus, HIV, group B streptococci, chlamydia trachomatis, and hepatitis virus $\mathrm{B}$ and $\mathrm{C}$ were excluded. The case samples were compared with a control population consisted of 81 samples of normal placental tissue. The healthy controls included in this study were all from fetal portion of term placental tissue and were collected immediately after term delivery.
2.2. Genomic DNA Analysis. Genomic DNA was extracted from formalin-fixed paraffin-embedded fetal tissue and normal term placental tissue (fetal portion) samples using igenomic CTB DNA Extraction Mini Kit according to the protocol (iNtRON Biotechnology, Inc., Korea). To determine the genotypic pattern of PvuII ( $\mathrm{T}>\mathrm{C}$, rs2234693) and XbaI (A > G, rs9340799) polymorphisms in intron 1 of ESR1 gene, we used polymerase chain reaction followed by restriction fragment length polymorphism method (PCRRFLP). A PCR fragment of $346 \mathrm{bp}$ consisting of the both base pair changes by the primers (forward primer: $5^{\prime}$ GATATCCAGGGTTATGTGGCA- $3^{\prime}$ and reverse primer: $5^{\prime}$ AGGTGTTGCCTATTATATTAACCTTGA-3') was amplified [3]. The total volume of PCR reaction was $20 \mu \mathrm{L}$ containing $50 \mathrm{ng}$ genomic DNA, $10 \mathrm{pM}$ of primers, $0.2 \mathrm{mM}$ dNTP, $2 \mathrm{mM} \mathrm{MgCl}_{2}, 2 \mu \mathrm{L}$ of $10 \mathrm{x}$ buffer, and $1 \mathrm{U}$ of Taq DNA polymerase (Fermentas, Vilnius, Lithuania). PCR conditions were as follows: initial denaturation at $94^{\circ} \mathrm{C}$ for $5 \mathrm{~min}, 35$ cycles with denaturation at $94^{\circ} \mathrm{C}$ for $45 \mathrm{sec}$, annealing at $53^{\circ} \mathrm{C}$ for $45 \mathrm{sec}$, and extension at $72^{\circ} \mathrm{C}$ for $45 \mathrm{sec}$ followed by 1 cycle of a final extension at $72^{\circ} \mathrm{C}$ for $7 \mathrm{~min}$. After performing the PCR, the amplification product of $346 \mathrm{bp}$ was digested overnight at $37^{\circ} \mathrm{C}$ with $\mathrm{PvuII}$ and $\mathrm{XbaI}$ restriction enzymes (TaKaRa, Otsu, Japan). The digested products were detected on $3 \%$ agarose gel electrophoresis.

For rs9340799 SNP after the digestion of 346 bp amplified product, two fragments of 148 and $198 \mathrm{bp}$ were observed in the presence of $\mathrm{XbaI}$ restriction site in which $A$ allele is present. For rs2234693 SNP, in the presence of $T$ allele due to the presence of PvuII restriction site, two fragments of 103 and 243 bp were identified from a digested $346 \mathrm{bp}$ amplified product. The presence of restriction site was indicated by " $p$ or $x$ " allele, while the absence was shown by " $P$ or $X$ " allele for PvuII and XbaI polymorphisms, respectively.

Fifteen percent of the PCR samples were sequenced to confirm the PCR-RFLP results using the ABI PRISM 3730 automated sequencer (Applied Biosystems, Foster City, Calif).

2.3. Statistical Analysis. Genotype frequencies were compared in cases and control groups. The SPSS version 16 software was used for all of the statistical analysis. Quantitative variables were evaluated by the student's $t$-test, while the $\chi^{2}$ test was used for analyzing the qualitative variables. The agreement with the Hardy-Weinberg expectations for the genotype distributions was also confirmed by $\chi^{2}$ test. A $P$ value $\leq 0.05$ was considered to be statistically significant.

\section{Result}

Totally, 161 tissue samples were recruited in this study. These samples were provided from 80 spontaneously aborted fetuses that were kept as formalin-fixed paraffin-embedded tissue as spontaneous abortion (SA) group, and 81 normal term placental tissue as control group.

The mean of maternal age in healthy and SA groups was $27.7 \pm 5.7$ and $28.08 \pm 5.4$ years, respectively $(P=0.7)$. The genotype distributions of $P v u I I$ and $X b a I$ polymorphisms in studied population were in the Hardy-Weinberg equilibrium. 


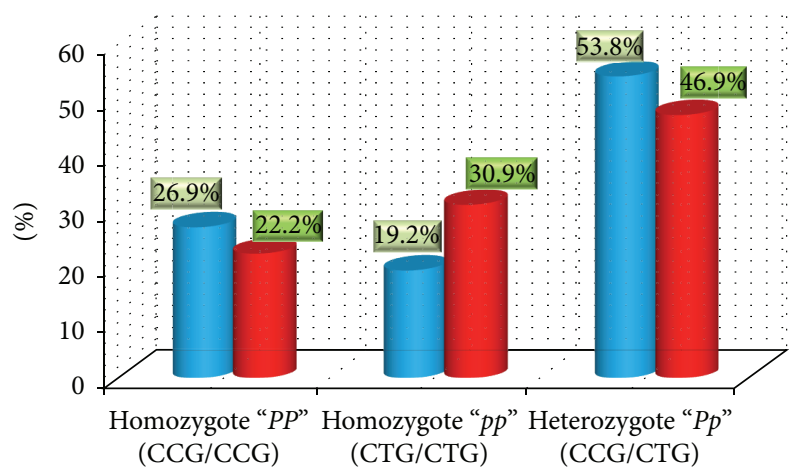

(a)

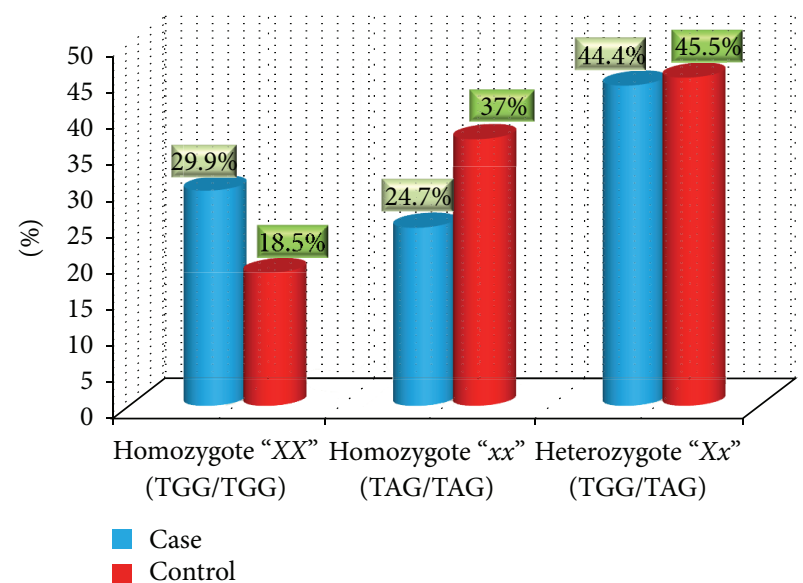

(b)

FIgure 1: (a) The distribution of PvuII genotypes among spontaneous abortion group and control groups $(P=0.2)$. (b) The distribution of $\mathrm{XbaI}$ genotypes among spontaneous abortion group and control groups $(P=0.1)$. The horizontal axis shows the three genotypes of each SNP, and the vertical axis shows the genotype frequencies in the spontaneous abortion and control groups.

TABLE 1: Haplotype frequencies of PvuII and XbaI polymorphisms in healthy and spontaneous abortion groups.

\begin{tabular}{lcc}
\hline \multirow{2}{*}{ Group } & \multicolumn{2}{c}{ Genotypes, $n(\%)$} \\
& $p p x x$ & Other combined genotypes \\
\hline Spontaneous abortion & $12(15.0 \%)$ & $68(85.0 \%)$ \\
Healthy & $25(30.9 \%)^{*}$ & $56(69.1 \%)$ \\
\hline
\end{tabular}

${ }^{*} P=0.01$ ( $P$ value, two-sided, from $\chi^{2}$ test).

The frequencies of PvuII genotypes in healthy controls were $18(22.2 \%), 25(30.9 \%)$, and $38(46.9 \%)$ for $P$, $p p$, and $P p I$, respectively. The frequencies of $P P$, $p p$, and $P p$ in SA group were $21(26.9 \%), 15(19.2 \%)$, and $42(53.8 \%)$, respectively. The frequencies of $X X, x x$, and $X x$ genotypes were $15(18.5 \%), 30(37.0 \%)$, and $36(45.5 \%)$ in healthy controls, as well as $23(29.9 \%), 19(24.7 \%)$, and $36(44.4 \%)$ in the SA group, respectively (Figure 1 ).

The frequency of $p p$ genotype of the PvuII and $x x$ genotype of $X b a I$ were lower in SA group compared to those of healthy controls ( $p p$ versus $P P+P p$ and $x x$ versus $X X$ $+X x ; P$ value $=0.09$ ). However, there were no statistically significant differences between SA and healthy groups in genotype distribution of ESR1 PvuII and XbaI separately. In haplotype analysis $p p x x$ genotype was significantly more frequent in healthy fetus in comparison to SA group ( $P=$ 0.01 , odds ratio $=2.530,95 \%$ CI: $1.167-5.485)$ (Table 1$)$.

As shown in Table 2, a significant correlation was found between the ESR1 XbaI and PvuII polymorphisms ( $P P$ with $X X$ and $p p$ with $x x$ genotypes $(P<0.01)$, reflecting the known linkage disequilibrium between the two SNPs [23].

\section{Discussion}

Estrogen plays a pivotal role during pregnancy. Studies reported that a considerable amount of estrogen is raised by the human placenta throughout pregnancy. It is completely
TABle 2: The correlation of PvuII and XbaI polymorphisms in the population.

\begin{tabular}{lccc}
\hline & \multicolumn{3}{c}{$P V U I^{*}$} \\
& $P P$ & $p p$ & $P p$ \\
\hline$X_{b a I^{*}}$ & & & \\
$X X \%(N)$ & $86.8(33)^{*}$ & $2.6(1)$ & $10.5(4)$ \\
$x x \%(N)$ & $2(1)$ & $75.5(37)^{*}$ & $22.4(11)$ \\
$X x \%(N)$ & $7(5)$ & $1.4(1)$ & $91.5(65)$ \\
${ }^{*} P=0.000$. & & &
\end{tabular}

known that estrogen produced by placenta is involved in the physiological procedures which are crucial for fetal growth and development during both extrauterine and intrauterine periods of life [4]. Since estrogen effects are modulated through estrogen receptors, variations in the ESR could have an important influence on its related procedures that provide pregnancy maintenance [15].

Some contradicting results of the role of ESR1 polymorphisms in spontaneous abortion or infertility were reported. In this study, for the first time, we investigated a possible association between ESR1 variants and spontaneous abortion in the fetal genome.

Several studies have reported strong linkage disequilibrium between PvuII and XbaI polymorphisms. These polymorphisms are located in the first intron of ESR1, and the linkage disequilibrium might be as a result of approximately $50 \mathrm{bp}$ distance between them. Such that allele $p$ (PvuII positive restriction site) is associated with $x$ allele ( $\mathrm{XbaI}$ positive restriction site) as well as allele $P$ ( $P v u I I$ negative restriction site) being linked with $X$ allele ( $X b a I$ negative restriction site) $[2,22,23]$. Interestingly, in our study we found a significant correlation of $p p$ genotype of $P v u I I$ polymorphism with $x x$ genotype of $X b a I$ and $P P$ genotype with $X X$ as well $(P=$ $0.000)$. 
Also, our findings demonstrated a lower frequency of $p p$ and $x x$ genotypes of $P v u I I$ and $X b a I$ polymorphisms in the SA group compared with that in healthy controls.

A genetic haplotype is identified as a combination of sets of alleles on the same chromosomal segment that tend to be transmitted as a block [24]. When we combined PvuII and $X b a I$ genotypes into haplotypes, a statistically significant difference between control and SA groups for $p p x x$ genotype combination with the higher frequency of $p p x x$ in the healthy controls was observed $(P=0.01)$, verifying the protective role of $p p x x$ genotype against spontaneous abortion. The consistent results were observed in a study of the PvuII and XbaI gene polymorphisms on a sample of Italian women in which Corbo et al. demonstrated a significantly lower number of abortions among $p p$ homozygote women compared with the carriers of $P P$ or $P p$ genotypes. Furthermore, a significant association of $p p x x$ genotype with lower number of abortions among the Italian women was reported. Simultaneously, in a sample of African-Ecuadorian women, it had been indicated that women carrying $p p$ and $p p x x$ genotypes were correlated with higher number of children [2]. Also, Corbo et al. demonstrated that various reproductive behaviors and environment may affect the impact of ESR1 genotypes on fertility $[2,17]$. In another study among premature infants, Derzbach et al. showed that any homozygotes for PvuII polymorphism, including $P P$ or $P p$, have a higher risk of at least one of the most common complications in perinatal period [25].

M'Rabet et al. demonstrated a potential role of PvuII allelic variants for infertility prediction among women at risk of premature ovarian aging with a higher frequency of the $P P$ genotype of PvuII polymorphism [26].

Pineda et al. found that the maternal TA haplotype (or $p x)$ of $P v u I I$ and $X b a I$ polymorphisms were associated with the increased risk of spontaneous abortion in women with miscarriages [3].

Other study in relation to unexplained female infertility detected the $P$ allele of $P v u I I$ polymorphism as a risk factor for females' idiopathic infertility, whereas $X$ allele of $X b a I$ had been reported to play a protective role regarding this condition [27].

In other studies, enhanced quality and number of follicles, mature oocytes, and fertilization rate among patients undergoing IVF were associated with PvuII CC (PP) genotype of ESR1 [18, 20, 21, 28].

Silva et al. revealed an association of $x x$ and $p p x x$ genotypes of PvuII and XbaI polymorphisms with spontaneous abortion in a population of postmenopausal women [29].

Since ethnic/race specific associations of ESR1 gene have been reported [24], contradiction among different investigations could be attributed to variations in ethnic groups. Indeed, the specific influence of gene polymorphisms and environmental factors could be different in various populations.

Several mechanisms could be explained for phenotypic effects of an intronic polymorphism [22]. Weickert et al. indicated that decreased levels of ESR1 mRNA were associated with PP genotype of PvuII polymorphism in postmortem brain tissue of schizophrenics. Reduced stability of ESR1
mRNA was found to be a result of $P$ allele incidence [30]. It is demonstrated that ESR1 gene polymorphisms can alter the function of estrogen receptor, but the exact biological mechanism remains unclear (or unknown) yet [24].

It has been reported that the increased gene enhancer activity might alter transcription levels of the gene, but it remains disputed so far that how an enhancer exactly exerts its effect [31].

In vitro studies have revealed a different activity of enhancer, although not significantly, between ESR1 haplotypes. Interestingly, the maximum enhancer activity was found to be associated with $x$ allele and $p p x x$ genotype [32]. Thereby, regulation of ESR1 expression could be biased by ESR1 genetic variants [2]. Hence, by modifying ESR1 function, biological actions of estrogen as one of the most influential and prominent hormones for fetal-placental development throughout pregnancy are placed under the influence $[2,4]$.

Since there has not been sufficient research in relation to effects of fetal genetic variations of ESR1 on reproduction efficiency and risk of spontaneous abortion, more prospective studies with larger sample size in different populations are recommended. Also, the evaluating of ESR1 expression in relation with $P v u I I$ and $X b a I$ can be helpful to clear the functional role of these variations. This was a limitation of the current study that due to using formalin-fixed paraffin-embedded fetal tissue as sources of SA group, we could not asses this evaluation. Therefore, further investigations on ESR1 expression level influenced by the PvuII and XbaI gene polymorphisms in spontaneously aborted samples are required as well.

In conclusion, our results indicated a meaningful association of $p p x x$ genotype with the decreased risk of spontaneous abortion. According to the profound effects of estrogen on fetal growth and development, we hypothesize that reduced estrogen activity due to the variations in the ESR1 of the fetal genome could affect fetal and placental development and stability during pregnancy. Accordingly, our study suggests ESR1 as a candidate gene for spontaneous abortion. However, further investigations need to confirm the impact of single nucleotide polymorphisms on spontaneous abortions among high-risk subjects.

\section{Conflict of Interests}

The authors declare that they have no conflict of interests.

\section{Acknowledgments}

The authores wish to thank the personnel of the Ghiasi and Emam-Sajad hospitals of Tehran and EMRI (Endocrinology and Metabolism Research Institute of Tehran University of Medical Sciences) from Shariati Hospital for the valuable assistance in this study. They also thank Dr. Bagher Larijani for his supporting efforts on this work.

\section{References}

[1] L. Björnström and M. Sjöberg, "Mechanisms of estrogen receptor signaling: convergence of genomic and nongenomic actions 
on target genes," Molecular Endocrinology, vol. 19, no. 4, pp. 833842, 2005.

[2] R. M. Corbo, L. Ulizzi, L. Piombo, C. Martinez-Labarga, G. F. De Stefano, and R. Scacchi, "Estrogen receptor alpha polymorphisms and fertility in populations with different reproductive patterns," Molecular Human Reproduction, vol. 13, no. 8, pp. 537540, 2007.

[3] B. Pineda, C. Hermenegildo, J. J. Tarín, P. Laporta, A. Cano, and M. A. García-Pérez, "Alleles and haplotypes of the estrogen receptor alpha gene are associated with an increased risk of spontaneous abortion," Fertility and Sterility, vol. 93, no. 6, pp. 1809-1815, 2010.

[4] E. D. Albrecht and G. J. Pepe, "Estrogen regulation of placental angiogenesis and fetal ovarian development during primate pregnancy," The International Journal of Developmental Biology, vol. 54, no. 2-3, pp. 397-407, 2010.

[5] Y. P. Gambino, J. L. Maymó, A. Pérez-Pérez et al., "17Betaestradiol enhances leptin expression in human placental cells through genomic and nongenomic actions," Biology of Reproduction, vol. 83, no. 1, pp. 42-51, 2010.

[6] N. Ravindranath and N. R. Moudgal, "Use of tamoxifen, an antioestrogen, in establishing a need for oestrogen in early pregnancy in the bonnet monkey (Macaca radiata)," Journal of Reproduction and Fertility, vol. 81, no. 2, pp. 327-336, 1987.

[7] L. P. Menasce, G. R. M. White, C. J. Harrison, and J. M. Boyle, "Localization of the estrogen receptor locus (ESR) to chromosome 6q25.1 by FISH and a simple post-FISH banding technique," Genomics, vol. 17, no. 1, pp. 263-265, 1993.

[8] E. Enmark, M. Pelto-Huikko, K. Grandien et al., "Human estrogen receptor $\beta$-gene structure, chromosomal localization, and expression pattern," The Journal of Clinical Endocrinology \& Metabolism, vol. 82, no. 12, pp. 4258-4265, 1997.

[9] P. Kumar, A. Kamat, and C. R. Mendelson, "Estrogen receptor $\alpha(\mathrm{ER} \alpha)$ mediates stimulatory effects of estrogen on aromatase (CYP19) gene expression in human placenta," Molecular Endocrinology, vol. 23, no. 6, pp. 784-793, 2009.

[10] S. C. Hewitt and K. S. Korach, "Oestrogen receptor knockout mice: roles for oestrogen receptors $\alpha$ and $\beta$ in reproductive tissues," Reproduction, vol. 125, no. 2, pp. 143-149, 2003.

[11] M. Y. El-Zibdeh, "Dydrogesterone in the reduction of recurrent spontaneous abortion," The Journal of Steroid Biochemistry and Molecular Biology, vol. 97, no. 5, pp. 431-434, 2005.

[12] J. L. Alcázar and C. A. Ortiz, “Transvaginal color Doppler ultrasonography in the management of first-trimester spontaneous abortion," European Journal of Obstetrics Gynecology \& Reproductive Biology, vol. 102, no. 1, pp. 83-87, 2002.

[13] J. H. S. You and T. K. H. Chung, "Expectant, medical or surgical treatment for spontaneous abortion in first trimester of pregnancy: a cost analysis," Human Reproduction, vol. 20, no. 10, pp. 2873-2878, 2005.

[14] N. Suzumori and M. Sugiura-Ogasawara, "Genetic factors as a cause of miscarriage," Current Medicinal Chemistry, vol. 17, no. 29, pp. 3431-3437, 2010.

[15] S. Lehrer, M. Sanchez, H. K. Song et al., "Oestrogen receptor B-region polymorphism and spontaneous abortion in women with breast cancer," The Lancet, vol. 335, no. 8690, pp. 622-624, 1990.

[16] S. H. Yoon, Y. M. Choi, M. A. Hong et al., "Estrogen receptor alpha gene polymorphisms in patients with idiopathic premature ovarian failure," Human Reproduction, vol. 25, no. 1, pp. 283-287, 2010.
[17] R. M. Corbo, G. Gambina, and R. Scacchi, "How contemporary human reproductive behaviors influence the role of fertilityrelated genes: the example of the P53 gene," PLoS ONE, vol. 7, no. 4, article e35431, 2012.

[18] S. Altmäe, O. Hovatta, A. Stavreus-Evers, and A. Salumets, "Genetic predictors of controlled ovarian hyperstimulation: where do we stand today?" Human Reproduction Update, vol. 17, no. 6, pp. 813-828, 2011.

[19] K. Casazza, G. P. Page, and J. R. Fernandez, "The association between the rs2234693 and rs9340799 estrogen receptor $\alpha$ gene polymorphisms and risk factors for cardiovascular disease: a review," Biological Research for Nursing, vol. 12, no. 1, pp. 84-97, 2010.

[20] Ö. Ü. Ayvaz, A. Ekmekçi, V. Baltaci, H. I. Önen, and E. Ünsal, "Evaluation of in vitro fertilization parameters and estrogen receptor alpha gene polymorphisms for women with unexplained infertility," Journal of Assisted Reproduction and Genetics, vol. 26, no. 9-10, pp. 503-510, 2009.

[21] C. Sundarrajan, W.-X. Liao, A. C. Roy, and S. C. Ng, "Association of oestrogen receptor gene polymorphisms with outcome of ovarian stimulation in patients undergoing IVF," Molecular Human Reproduction, vol. 5, no. 9, pp. 797-802, 1999.

[22] A. Molvarec, Á. Vér, A. Fekete et al., "Association between estrogen receptor $\alpha$ (ESR1) gene polymorphisms and severe preeclampsia," Hypertension Research, vol. 30, no. 3, pp. 205-211, 2007.

[23] L. Becherini, L. Gennari, L. Masi et al., "Evidence of a linkage disequilibrium between polymorphisms in the human estrogen receptor $\alpha$ gene and their relationship to bone mass variation in postmenopausal Italian women," Human Molecular Genetics, vol. 9, no. 13, pp. 2043-2050, 2000.

[24] E. E. Sundermann, P. M. Maki, and J. R. Bishop, "A review of estrogen receptor $\alpha$ gene (ESR1) polymorphisms, mood, and cognition," Menopause, vol. 17, no. 4, pp. 874-886, 2010.

[25] L. Derzbach, A. Treszl, A. Balogh, B. Vásárhelyi, T. Tulassay, and J. J. Rigó, "Gender dependent association between perinatal morbidity and estrogen receptor-alpha PvuII polymorphism," Journal of Perinatal Medicine, vol. 33, no. 5, pp. 461-462, 2005.

[26] N. M'Rabet, R. Moffat, S. Helbling, A. Kaech, H. Zhang, and C. de Geyter, "The CC-allele of the PvuII polymorphic variant in intron 1 of the $\alpha$-estrogen receptor gene is significantly more prevalent among infertile women at risk of premature ovarian aging," Fertility and Sterility, vol. 98, no. 4, pp. 965-972, 2012.

[27] J.-W. Du, X.-R. Tao, K.-Y. Xu, L.-Y. Fang, and X.-L. Qi, "Polymorphisms in estrogen receptor- $\alpha$ are associated with idiopathic female infertility," Molecular Medicine Reports, vol. 4, no. 6, pp. 1239-1242, 2011.

[28] I. Georgiou, M. Konstantelli, M. Syrrou, I. E. Messinis, and D. E. Lolis, "Oestrogen receptor gene polymorphisms and ovarian stimulation for in-vitro fertilization," Human Reproduction, vol. 12, no. 7, pp. 1430-1433, 1997.

[29] I. V. Silva, L. C. D. Rezende, S. P. Lanes et al., "Evaluation of PvuII and XbaI polymorphisms in the estrogen receptor alpha gene (ESR1) in relation to menstrual cycle timing and reproductive parameters in post-menopausal women," Maturitas, vol. 67, no. 4, pp. 363-367, 2010.

[30] C. S. Weickert, A. L. Miranda-angulo, J. Wong et al., "Variants in the estrogen receptor alpha gene and its mRNA contribute to risk for schizophrenia," Human Molecular Genetics, vol. 17, no. 15, pp. 2293-2309, 2008.

[31] M. Banditt, T. Koller, and J. M. Sogo, "Transcriptional activity and chromatin structure of enhancer-deleted rRNA genes in 
Saccharomyces cerevisiae," Molecular and Cellular Biology, vol. 19, no. 7, pp. 4953-4960, 1999.

[32] H. Maruyama, H. Toji, C. R. Harrington et al., "Lack of an association of estrogen receptor $\alpha$ gene polymorphisms and transcriptional activity with Alzheimer disease," Archives of Neurology, vol. 57, no. 2, pp. 236-240, 2000. 

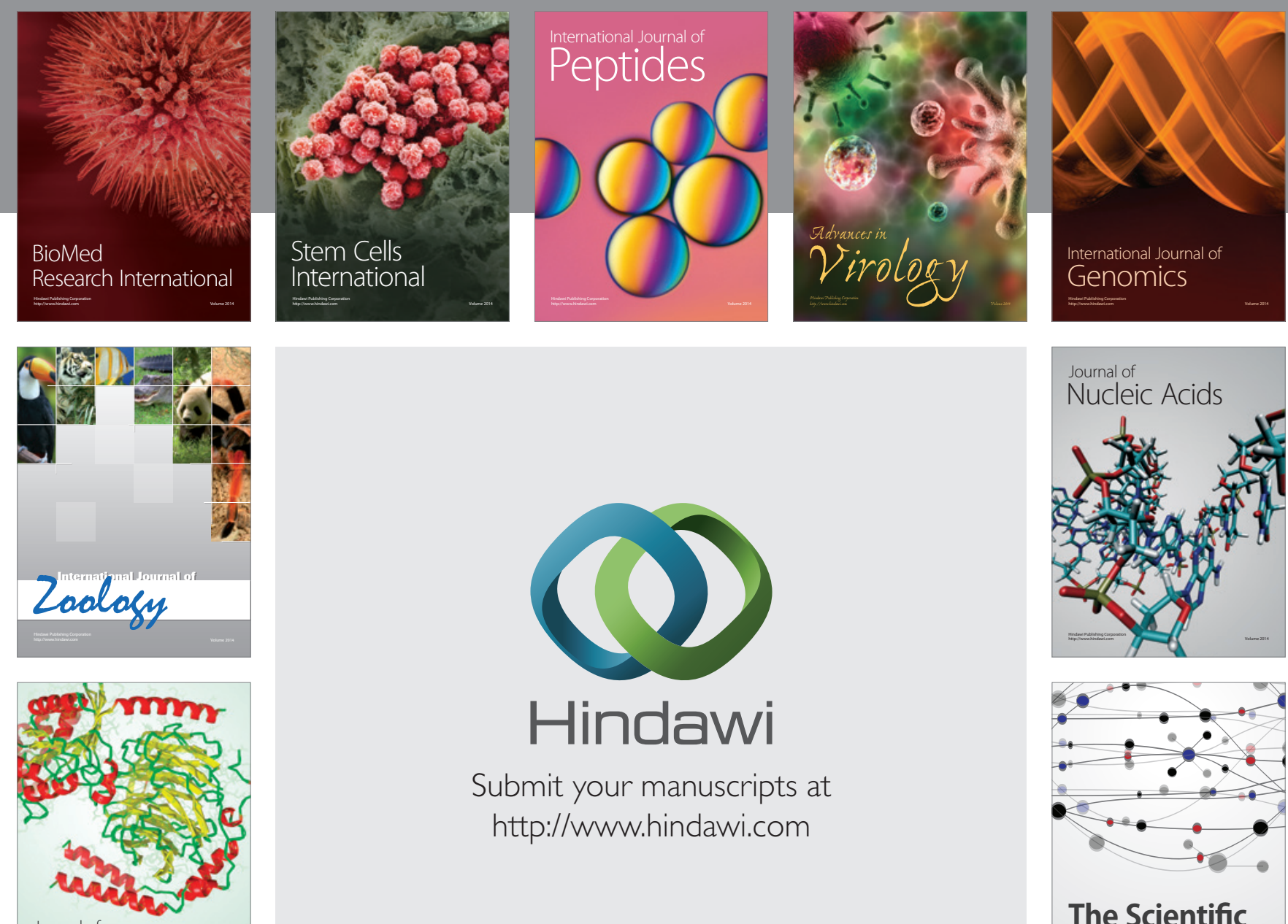

Submit your manuscripts at

http://www.hindawi.com

Journal of
Signal Transduction
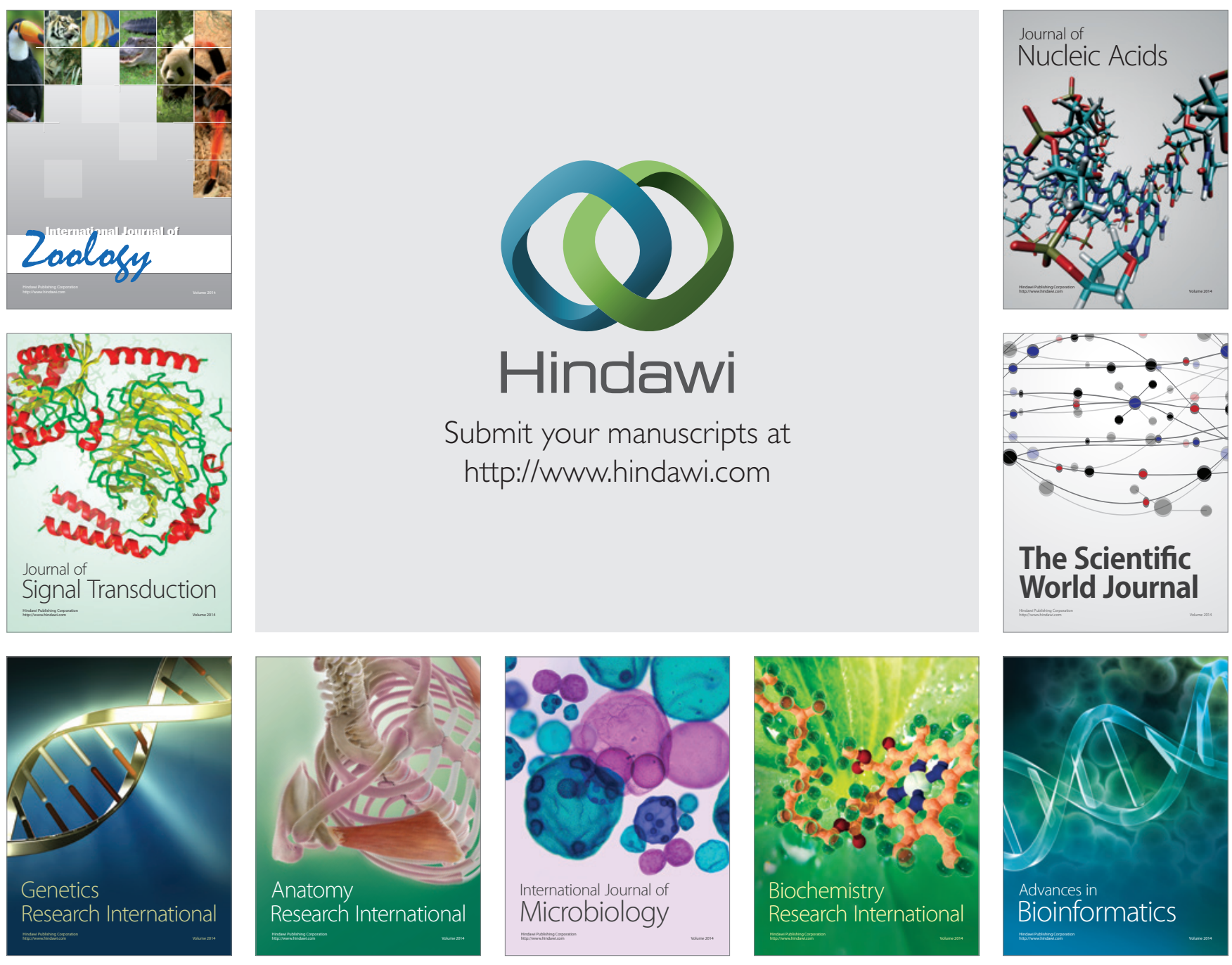

The Scientific World Journal
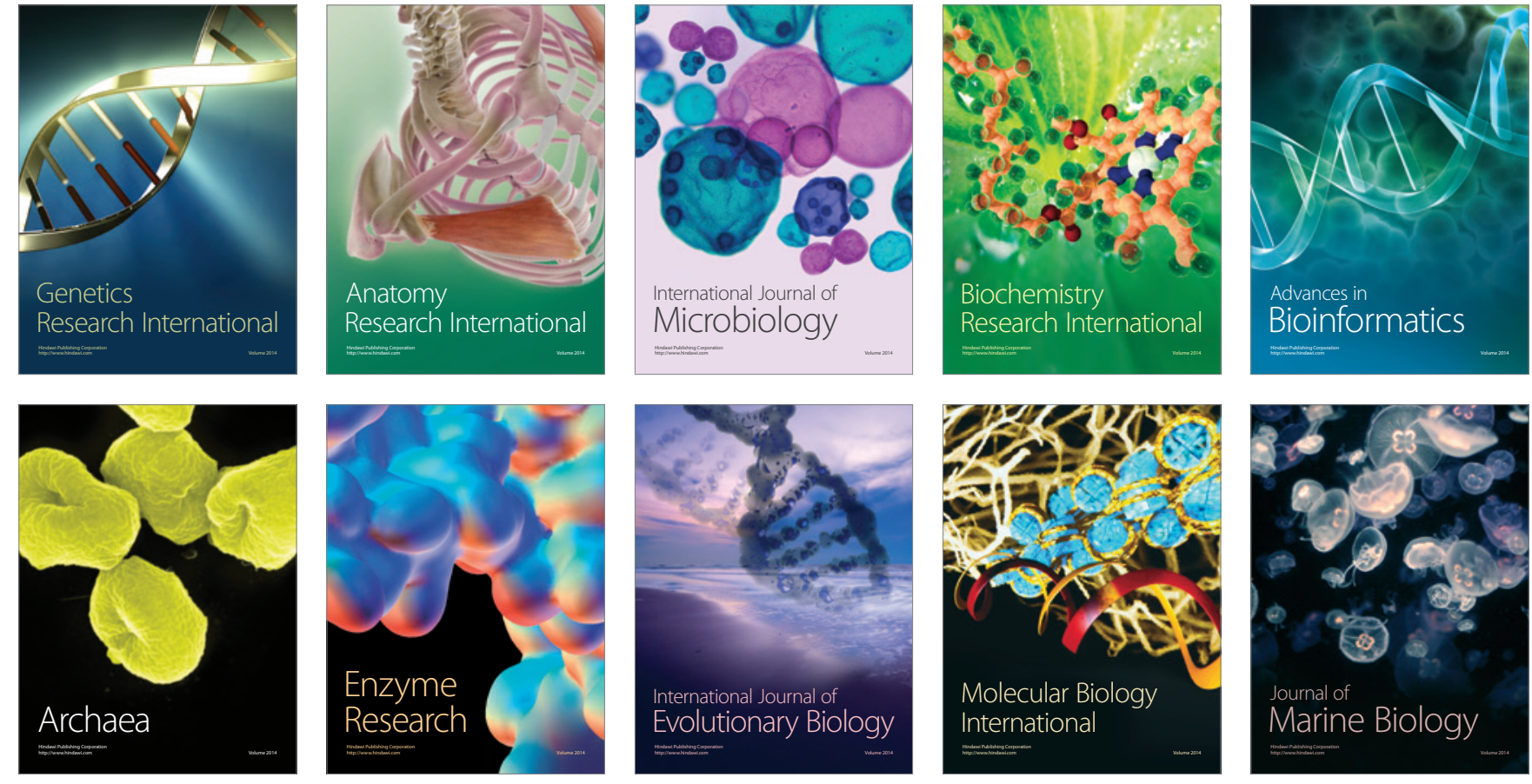